\title{
Practical Consensus Recommendations for Optimizing Risk versus Benefit of Chemotherapy in Patients with HR Positive Her2 Negative Early Breast Cancer in India
}

\author{
Purvish M. Parikh $\quad$ Gouri Shankar Bhattacharyya ${ }^{2} \quad$ Ghanshyam Biswas $^{3} \quad$ Arvind Krishnamurty $^{4}$ \\ Dinesh Doval $^{5}$ Anil Heroor $^{6}$ Sanjay Sharma ${ }^{7}$ Ramakant Deshpande $^{7, \odot ~ H a r i t ~ C h a t u r v e d i ~}{ }^{8}$ \\ S.P. Somashekhar ${ }^{9, \odot} \quad$ Govind Babu ${ }^{10, \odot} \quad$ G. Krishna Reddy ${ }^{11} \quad$ Diptendra Sarkar ${ }^{12} \quad$ Chirag Desai $^{13}$ \\ Hemant Malhotra ${ }^{14} \quad$ Nitesh Rohagi $^{15} \quad$ Ajay Bapna ${ }^{16} \quad$ S.S. Alurkar ${ }^{17}$ Prasad Krishna ${ }^{18, \odot} \quad$ S.V.S. Deo ${ }^{19}$ \\ Anurag Shrivastava ${ }^{20}$ Prakash Chitalkar ${ }^{21}$ Saroj Kumar Majumdar ${ }^{22}$ Devanhalli Vijay ${ }^{23}$ \\ Aniket Thoke $^{24}$ K.S. Udupa ${ }^{25}$ Jyoti Bajpaii ${ }^{26}$ G.K. Rath ${ }^{27}$ Palanki Satya Dattatreya ${ }^{28}$ \\ Shailesh Bondarde ${ }^{29}$ Shekhar Patil ${ }^{10}$
}

${ }^{1}$ Mumbai Oncocare Centers, Mumbai, India

${ }^{2}$ Fortis Hospital, Anandapur, Kolkata, West Bengal, India

${ }^{3}$ Medical Oncology, Sparsh Hospital \& Critical Care, Bhubaneswar, India

${ }^{4}$ Surgical Oncology, Cancer Institute (Adyar), Chennai, India

${ }^{5}$ Medical Oncology, Rajiv Gandhi Cancer Institute and Research Centre, Delhi, India

6Surgical Oncology, Fortis Hospital, Mumbai, India

${ }^{7}$ Surgical Oncology, Asian Cancer Institute, Mumbai, India

${ }^{8}$ Surgical Oncology, Max Institute of Cancer Care, Delhi, India

${ }^{9}$ Surgical Oncology, Manipal Comprehensive Cancer Center, Manipal Hospital, Bangalore, India

${ }^{10}$ Medical Oncology, HCG Cancer Hospital, Bengaluru, India

${ }^{11}$ Medical Oncology, Manipal Hospitals, Vijaywada, India

12 Surgical Oncology, Institute of Post-Graduate Medical Education and Research and Seth Sukhlal Karnani Memorial Hospital, Kolkata, India

${ }^{13}$ Medical Oncology, Vedanta Institute of Medical Sciences,

Ahmedabad, India

${ }^{14}$ Medical Oncology, MG Hospital, Jaipur, India

${ }^{15}$ Medical Oncology, Max Institute of Cancer Care, Delhi, India

${ }^{16}$ Medical Oncology, Bhagwan Mahaveer Cancer Hospital and Research Centre, Jaipur, India

${ }^{17}$ Medical Oncology, Apollo Hospital, Ahmedabad, India
Address for correspondence Purvish M. Parikh, MD, PHD, DNB, ECMO, FICP, CPI, Mumbai Oncocare, Mumbai 400013, India (e-mail: purvish1@gmail.com).

${ }^{18}$ Medical Oncology, Mangalore Institute of Oncology, Mangalore, India

${ }^{19}$ Surgical Oncology, All India Institute of Medical Sciences, Delhi, India

${ }^{20}$ Surgery, All India Institute of Medical Sciences, Delhi, India

${ }^{21}$ Medical Oncology, Sri Aurobindo Medical College and

Postgraduate Institute, Indore, India

${ }^{22}$ Radiation Oncology, AlIMS, Bhubaneswar, India

${ }^{23}$ Surgical Oncology, HCG Cancer Hospital, Ahmedabad, India

${ }^{24}$ Radiation Oncology, Sanjeevani CBCC USA Cancer Hospital, Raipur, India

${ }^{25}$ Medical Oncology, Kasturba Medical College, Manipal, India

${ }^{26}$ Medical Oncology, Tata Memorial Hospital, Mumbai, India

27Radiation Oncology, DR. B.R.A. Institute Rotary Cancer Hospital, Delhi, India

${ }^{28}$ Medical Oncology, Omega Hospitals, Hyderabad, India

${ }^{29}$ Medical Oncology, Shatabdi Super Speciality Hospital, Nashik, India

\section{South Asian J Cancer 2021;10:213-219.}

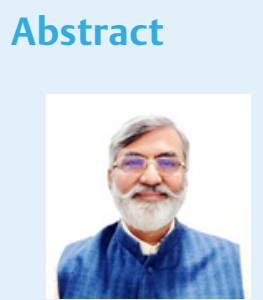

Shubhra Ramchandani
Breast cancer is a public health challenge globally as well as in India. Improving outcome and cure requires appropriate biomarker testing to assign risk and plan treatment. Because it is documented that significant ethnic and geographical variations in biological and genetic features exist worldwide, such biomarkers need to be validated and approved by authorities in the region where these are intended to be used. The use of western guidelines, appropriate for the Caucasian population, can lead to inappropriate overtreatment or undertreatment in Asia and India. A virtual meeting of domain experts discussed the published literature, real-world practical experience,
DOI https://doi.org/10.1055/s-0041-1742080 ISSN 2278-330X

How to cite this article: Parikh P. M, Bhattacharyya G. S, Biswas G, et al. Practical Consensus Recommendations for Optimizing Risk versus Benefit of Chemotherapy in Patients with HR Positive Her2 Negative Early Breast Cancer in India. South Asian J Cancer 2021;10(4):213-219.
(C) 2021. MedIntel Services Pvt Ltd.

This is an open access article published by Thieme under the terms of the Creative Commons Attribution-NonDerivative-NonCommercial-License, permitting copying and reproduction so long as the original work is given appropriate credit. Contents may not be used for commercial purposes, or adapted, remixed, transformed or built upon. (https://creativecommons.org/licenses/by-nc-nd/4.0/).

Thieme Medical and Scientific Publishers Private Ltd A-12, Second Floor, Sector -2, NOIDA -201301, India 
Keywords

- avoiding financial distress

- avoiding toxicity

- COVID-19

- low- and middle-income countries

- personalized therapy

- precision oncology

- saving lives and results of opinion poll involving 185 oncologists treating breast cancer across 58 cities of India. They arrived at a practical consensus recommendation statement to guide community oncologists in the management of hormone positive (HR-positive) Her2-negative early breast cancer (EBC). India has a majority (about 50\%) of breast cancer patients who are diagnosed in the premenopausal stage (less than 50 years of age). The only currently available predictive test for HR-positive Her2-negative EBC that has been validated in Indian patients is CanAssist Breast. If this test gives a score indicative of low risk $(<15.5)$, adjuvant chemotherapy will not increase the chance of metastasis-free survival and should not be given. This is applicable even during the ongoing COVID-19 pandemic.

\section{Introduction}

Breast cancer is a public health challenge in many parts of the world including India. ${ }^{1,2}$ In India, our age adjusted rate is as high as 25.8 per 100,000 women and mortality rate is 12.7 per 100,000 women. In major cities, the age-adjusted incidence rate is even higher, being 41 per 100,000 women for Delhi, 37.9 for Chennai, 34.4 for Bangalore, and 33.7 for Thiruvananthapuram. ${ }^{3-6}$ From 1982 to 2014, a significant increase in age-adjusted rates has been documented in all our population-based cancer registries (PBCRs); annual percentage increase being 2.84\% in Bangalore and 2.44\% in Delhi. Even the rural areas showed a significant increase, being $1.87 \%$ in Barshi. Projection for breast cancer in India by 2020 suggests we will be having as many as 17,97,900 cases. Our median age at diagnosis has been reported as 44.6 years (range: $23-90$ years), with $33 \%$ being < 40 years of age, with $66.16 \%$ of these patients already in Stage III at initial diagnosis. One of the main reasons for the same is that majority of our patients (2011 data) present 1 year after the onset of clinical symptoms. Real-world data from three Indian centers, on patients with non-metastatic breast cancer who underwent potentially curative surgery as their initial treatment, included 3,453 patients. ${ }^{7}$ This included $11.75 \%$ in stage I, $66.79 \%$ in stage II, and $21.64 \%$ in sage III. Hormone receptor-positive/HER2-negative formed $55.2 \%$ of cases, triple-negative breast cancer (TNBC) was seen in $24.2 \%$ and hormone receptor any/HER2-positive cases formed 20.6\%. For the 3,453 patients, the 5-year OS was $94.1 \%$ (93.25-94.98) and DFS was $88.1 \%(86.96-89.31)$. This is the largest dataset of early breast cancer patients from India with survival outcome analysis and can therefore serve as a benchmark for future studies.

To improve the outcome, especially the chance of cure, accurate predictive testing and better understanding of the pharmacogenomic variations are crucial ${ }^{8.9}$ The use of western guidelines without comprehending the difference in natural history, disease biology, and pharmacogenomics can lead to either overtreatment (with accompanied exposure to toxicity) or undertreatment (with associated reduced chance of cure)..$^{10,11}$

\section{Materials and Methods}

A virtual meeting of domain expert oncologists was organized by Integrated Academic Society of Clinical Oncology (IASCO) to discuss and arrive at a consensus statement to guide community oncologists in the management of HR-positive Her2-negative EBC. The discussion developed from the published evidence as well as pragmatic analysis of practical experience in real-life management of patients by these national and international experts. ${ }^{12}$ The experts were also provided results of an online poll of oncologists (from various specialties: medical oncologists, surgical oncologists, radiation oncologists, molecular oncologists, and policy makers) who had previously shown academic interest in the management of breast cancer. ${ }^{13}$ The domain experts then arrived at this consensus statement for the benefit of community oncologists so that they would have easy access to a ready-to-use practical recommendation.

As part of the background work, the group members were provided current published evidence. Domain expert members were encouraged to share their experiences and give their opinion, which was taken into consideration while drafting and finalizing this consensus statement. ${ }^{10,12,13}$

\section{Results}

A total of 185 oncologists treating breast cancer participated in the survey (206 were invited) from 58 cities across India. Their specialties included medical oncology in 119 (64\%), surgical oncology in 45 (24\%), radiation oncology in 16 (9\%), and other oncology in the remaining 5 (3\%).

The question-wise analysis showed the following:

a. To the question, do clinically low-risk HR+ve/Her2-ve T1N0 breast cancer patients benefit from chemotherapy (CT), the majority $(72 \% ; 133 / 185)$ were of the opinion that benefit was expected only in the minority. Another $7 \%$ $(13 / 185)$ did not perceive any benefit at all. Only $21 \%$ (39/133) answered in the affirmative without any rider.

b. When asked whether biomarker-based prognostic tests help identify the subset of clinically low-risk patients who 
will benefit from chemotherapy, the answer was "Yes" by 181 (98\%) and "No" by 4 (2\%). In addition, 78 (42\%) wanted the test to be cost-effective.

c. The use of such a biomarker testing was not uniform amongst the responders. A total of $32(17 \%)$ did not want to use such a test. Amongst the 152 (82\%) who use it, 45 (24\%) use the test for all eligible patients, whereas 108 (58\%) would use it only if the patient was interested in avoiding chemotherapy.

d. To the question whether age influences the decision when treatment objective is potential cure, the majority (184, 99.9\%) would not allow age to influence the treatment decision. A total of $14(8 \%)$ said this was because older patients should not be undertreated. Another 18 (10\%) stated this was because younger patients should not be over-treated. The majority $(152 ; 82 \%)$ said both the reasons were appropriate.

e. When asked whether ethnic and geographic variations have a significant impact on biomarker test interpretation and their use for clinical management decision-making, 136 (74\%) said "Yes"; 6 (3\%) said "No"; and 43 (23\%) were not sure (-Fig. 1).

f. The survey participants were also asked whether regulatory authorities (Drugs Controller General of India [DCGI] and Indian Council for Medical Research [ICMR]) should take into consideration validated data from Indian patients before recommending use of biomarker testing. A total of 150 (81\%) answered in the affirmative, 11 (6\%) said "No," and 24 (13\%) were not sure.

g. When asked regarding specific commercially available biomarker test (Oncotype DX, Mammaprint, Prosigna and Endopredict) for HR-positive Her2-negative EBC, the majority stated that their data have not included sufficient patients below 50 years of age/premenopausal patients (122; 66\%). Another 20 (11\%) did not agree with this statement, whereas the remaining 43 (23\%) survey responders were not sure.

h. A comparable number also confirmed that they were aware that Oncotype Dx RS score had different treatment implications in patients up to the age of 50 years

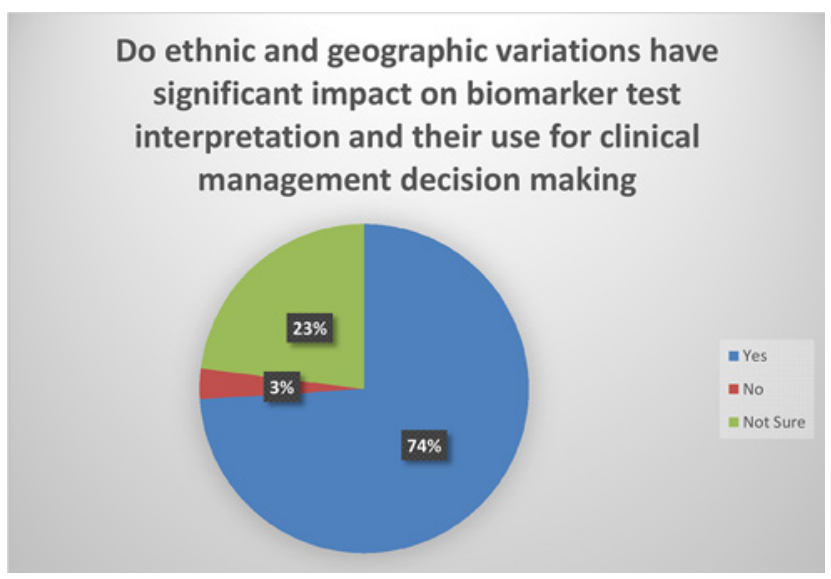

Fig. 1 Survey $(N=185)$ : Do ethnic and geographic variations have significant impact on biomarker test interpretation and their use for clinical management decision making? versus those who were older (116; 63\%). Another $19(10 \%)$ were not aware of this and the remaining 50 (27\%) were not sure.

i. When asked about CanAssist Breast prognostic test, 98 (53\%) were convinced about its clinically validation and applicability for Indian patients based on the data published in international peer-reviewed journals. Therefore, they used it in eligible patients in their practice. Another 20 (11\%) were not convinced and the remaining 67 (36\%) were unsure.

j. In response to the question whether they would withhold treatment if CanAssist Breast indicated low risk of recurrence, 109 (59\%) answered in the affirmative, 19 (10\%) would not withhold treatment, and the remaining 57 (31\%) were unsure.

$k$. To the question about deciding in favor of recommending chemotherapy if the CanAssist Breast test indicated high risk of recurrence (in the presence of clinically low risk), 125 (68\%) would give the chemotherapy, 7 (3\%) would not give it, and the remaining 53 (29\%) were not sure ( - Fig. 2).

Taking into consideration the survey results, the currently available published data, personal experience in the real-world, and the discussions of the domain expert oncologists, the following practical consensus recommendation was arrived at unanimously (- Table 1 ).

We have condensed the consensus recommendations to a consensus flowchart for treatment of patients who are eligible for a prognostic test ( - Fig. 3 ).

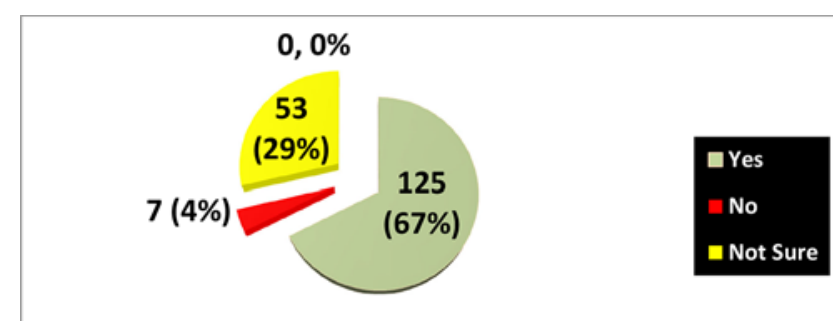

Fig. 2 Survey $(N=185)$ : If CanAssist Breast indicates high risk of recurrence in a patient with clinical low risk $H R+v e$ Her2-ve EBC, would you give adjuvant chemotherapy?

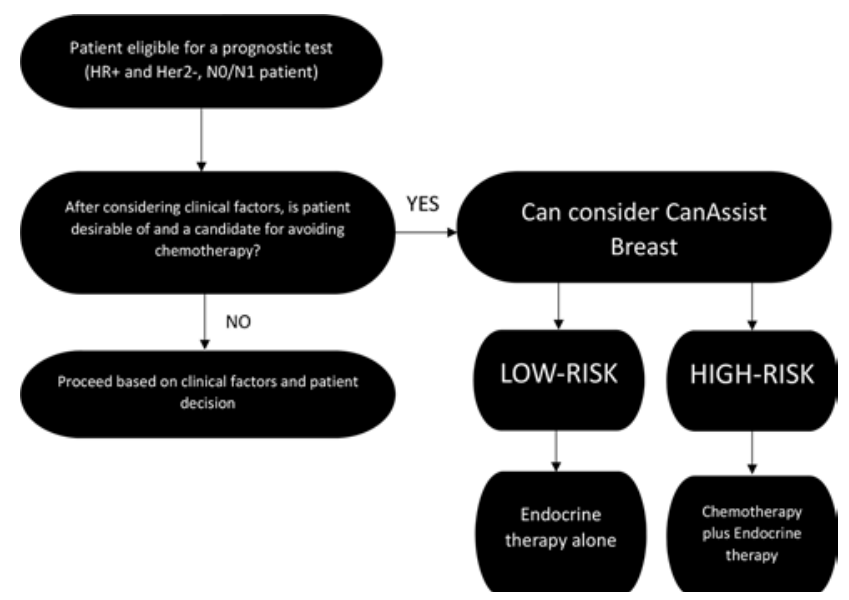

Fig. 3 Consensus flowchart for treatment of HR+ Her2-patients who are eligible for prognostic tests, based on the survey of 185 oncologists in India. 
Table 1 Practical Consensus Recommendation for optimizing benefit of chemotherapy the management of HR-positive Her2-negative early breast cancer

\begin{tabular}{|c|c|}
\hline $\begin{array}{l}\text { Sr } \\
\text { No. }\end{array}$ & Consensus Recommendation \\
\hline 1 & $\begin{array}{l}\text { Patients with HR-positive Her2-negative early breast cancer } \\
\text { can benefit from chemotherapy but only in a small fraction }\end{array}$ \\
\hline 2 & $\begin{array}{l}\text { If not identified appropriately, some of these patients may } \\
\text { be overtreated with chemotherapy and exposed to poten- } \\
\text { tially avoidable chemotherapy and its hazards }\end{array}$ \\
\hline 3 & $\begin{array}{l}\text { Clinical features alone are not sufficiently robust in sepa- } \\
\text { rating such patients into low and high-risk category }\end{array}$ \\
\hline 4 & $\begin{array}{l}\text { In principle, Western guidelines rightly advocate the use } \\
\text { of multi-marker risk assessment tests for patients with } \\
\text { EBC. However, they differ significantly amongst them- } \\
\text { selves regarding specific details, including the selection } \\
\text { of patients based on axillary lymph node status and are } \\
\text { predominantly applicable to Caucasians }\end{array}$ \\
\hline 5 & $\begin{array}{l}\text { There exists published recommendations and guidelines } \\
\text { that clearly state that Asian patients need to be managed } \\
\text { differently as compared to other ethnic groups }\end{array}$ \\
\hline 6 & $\begin{array}{l}\text { There is a significant ethnic and geographical variations } \\
\text { in biological and genetic features, raising the question } \\
\text { regarding applicability and significance of prognostic and } \\
\text { predictive tests amongst patients groups not sufficiently } \\
\text { represented in the published validated data }\end{array}$ \\
\hline 7 & $\begin{array}{l}\text { Regulatory authorities in India, in their breast cancer } \\
\text { guidelines, have specifically stated that such tests should } \\
\text { not be used in clinical practice unless validated amongst } \\
\text { Indian patients }\end{array}$ \\
\hline 8 & $\begin{array}{l}\text { Most commercially available and validated predictive } \\
\text { tests (such as Oncotype DX, Mammaprint, Endopredict, } \\
\text { Prosigna) for EBC are applicable primarily in the post-men- } \\
\text { opausal age group and below the age of } 50 \text { years }\end{array}$ \\
\hline 9 & $\begin{array}{l}\text { India has a significant (about } 50 \% \text { ) number of breast cancer } \\
\text { patients who are diagnosed in the premenopausal stage }\end{array}$ \\
\hline 10 & $\begin{array}{l}\text { When tests change their cutoff values and/or have } \\
\text { different cutoff values for different age groups (such as } \\
\text { Oncotype DX), their robustness is questionable and can- } \\
\text { not be relied upon }\end{array}$ \\
\hline 11 & $\begin{array}{l}\text { The only currently available predictive test for HR-positive } \\
\text { Her2-negative EBC that has been validated in Indian } \\
\text { patients is CanAssist Breast }\end{array}$ \\
\hline 12 & $\begin{array}{l}\text { If an HR-positive Her2-negative EBC patient with clinical } \\
\text { low-risk features is found to have CanAssist Breast score } \\
\text { indicative of high risk, such a patient should be recom- } \\
\text { mended chemotherapy as part of the overall treatment } \\
\text { plan to increase the chance of potential cure }\end{array}$ \\
\hline 13 & $\begin{array}{l}\text { If an HR-positive Her2-negative EBC patient with clinical high } \\
\text { risk features is found to have CanAssist Breast score indicative } \\
\text { of low risk (score < 15.5), such a patient should be advised not } \\
\text { to have chemotherapy as part of the overall treatment plan, } \\
\text { without reducing the chance of potential cure }\end{array}$ \\
\hline 14 & $\begin{array}{l}\text { Use of these practical consensus recommendations will } \\
\text { assist real-world patient treatment decision-making by } \\
\text { avoiding cost/toxicity of chemotherapy in patients unlikely } \\
\text { to benefit from it. It will also ensure that patients with high } \\
\text { risk of recurrence are correctly selected to receive chemo- } \\
\text { therapy as part of their potentially curative treatment plan }\end{array}$ \\
\hline 15 & $\begin{array}{l}\text { These practical recommendations are applicable even } \\
\text { during the COVID-19 pandemic because patients with } \\
\text { HR-positive Her2-negative early breast cancer are treated } \\
\text { with curative intent }\end{array}$ \\
\hline
\end{tabular}

\section{Discussion}

Breast cancer continues to be an important public health problem in India, South Asia, and rest of the world as well. ${ }^{14}$

Approximately $20 \%$ of women diagnosed with EBC will experience recurrence at a distant site within 10 years. ${ }^{15,16}$

The challenge faced by the community oncologists' is to decide how to identify these high-risk patients and offer them appropriate adjuvant chemotherapy-avoiding unnecessary toxicity in those that would not benefit as well as ensuring that the rest are not denied a higher chance of cure. ${ }^{17-21}$

The wider implications of over treatment and under treatment are discussed well elsewhere and need to be considered in the process of arriving at the overall management plan for individual patients. ${ }^{22,23}$

There is a lot of interest in clinically low-risk patients with $\mathrm{EBC}$, and various biomarker tests help identify the "high risk" subset of patients who would benefit from adjuvant or neoadjuvant CT. ${ }^{24-26}$ This is not only important but also urgent because any delay in adjuvant therapy has been shown to worse survival in patients with nonmetastatic breast cancer. ${ }^{27,28}$

To make it cost-effective as well as not strain the infrastructure capacity, it is vital to define the group of patients that should undergo such testing. ${ }^{29}$

Unfortunately, western literature is fraught with conflicting or overlapping recommendations. For instance, the ESMO requires the use of prognostic tests for lymph node-negative (N0) patients. ${ }^{30,31}$ In contrast, ASCO and NCCN state it is required for N0 and 1-3 lymph node-positive (N1) patients. ${ }^{32}$ And the recommendation by AJCC is to use a multigene panel to downstage low-risk patients, without further specifications. $^{33}$

There is also substantial evidence about significant variations in the use and applicability of biomaker testing amongst ethnic and geographical diverse populations. ${ }^{34-37}$ Two groups of researchers studied the performance of first-generation prognostic test Mammaprint in Asians and found the percentage of high-risk patients significantly higher in the Korean $^{38}$ and Japanese ${ }^{39}$ cohorts that were studied, compared to the percentage of high-risk patients in Caucasian cohorts that were part of the MINDACT trial. ${ }^{39}$

Western literature continues to evolve regarding the value, application, score cutoff, number of risk groups, etc., with respect to biomarker testing in HR-positive Her2-negative EBC including the use of Oncotype DX, Mammaprint, Endopredict and Prosigna. ${ }^{40-44}$ Even when applied to the Caucasian population (population in whom their applicability has been validated), gray areas, conflicts, uncertainties, and difficulties continue to exist. What was the rationale and date on which risk score cutoff of Oncotype DX was changed? Why do these tests have different implications for patients below and above the age of 50 years, based on data from three large trials MINDACT, ${ }^{41}$ TAILORX, ${ }^{45}$ and RXPONDER ${ }^{46}$ ?

To understand more clearly, let us look at the results of a study amongst 100 patients with ER-positive EBC from Kuwait. ${ }^{47}$ The median age is 50 years (range: $38-74$ ), similar to what we see in India. The Oncotype DX test reported recurrence score $(\mathrm{RS})$ results being low $(<18)$ in 54 patients, 
intermediate $(\geq 18$ and $<30)$ in 34 , and high risk $(\geq 30)$ in 12 patients. In other words, the test did not provide any useful information in one-third (34\%) patients who formed the intermediate group. This is collaborated by the actual treatment decision, 17 (50\%) were recommended chemoendocrine therapy (CET) but only 5 received it; and in the other half who were advised endocrine therapy (ET) alone, 7 actually went on to receive CET. ${ }^{47}$

Skepticism about the value of Oncotype DX has even led to Germany revising its reimbursement policy for this test. ${ }^{48}$ Details of the Oncotype DX assay are shrouded in mystery, makings its interpretation and comparison by investigators to other assays extremely difficult, if not impossible. Specific problems include no information regarding the RNA amount used; missing measurement units in the single gene expression report; no citation of references in their original published study explaining how the recurrence score formula was arrived at; and vague information on the normalization of expression of genes. ${ }^{48}$

Disappointment has also led to oncologists going back to relying on clinicopathological data, until such time as a more robust and accurate test becomes available. ${ }^{49}$

When we discuss Indian patients, other factors also need to be considered. In the west, the majority of patients with breast cancer are in the elderly age group. In several countries, such as India, the situation is quite different-with about half of the patients being premenopausal.,3,50

These are some of the important reasons why separate recommendations and consensus statements from Asia are needed and have been published. ${ }^{51-54}$

In India, the regulatory authorities (DCGI and ICMR) have clearly recommended that such testing should not be used in clinical practice unless validated amongst Indian patients. ${ }^{55,56}$ Wang et $\mathrm{al}^{57}$ showed that OncotypeDx is not cost-effective even in low-risk patients. The cost-effectiveness analyses (CEAs) ignoring clinicopathological information are problematic, not only because they depart from clinical practice but also because they result in inappropriate conclusions. ${ }^{58}$

A recent study reported the results of a survey of 100 medical oncologists in India, 58\% reported using PREDICT online for adjuvant decision making, and 94\% felt that PREDICT online could be used as an alternative to genomic tools in a resource-constrained setting like ours. ${ }^{54}$

However, PREDICT and other online tools such as Adjuvant! have been shown to underperform when predicting the survival for Asian breast cancer patients. ${ }^{22,58,59}$ Currently Adjuvant! is not even available for use, it is being updated, during which time it has been offline for the past few years. Furthermore, reports suggest that given the suboptimal performance of online risk prediction models in various subgroups, they are not conducive to patient comprehension. ${ }^{60}$ These online models are also not part of any treatment guidelines, where multi-marker prognostic tests have found a home in various treatment guidelines.

Fortunately, CanAssist Breast is a tool that has been prospectively validated in Indian patients and results published in full-text articles in international journals of repute. ${ }^{61-64}$ CanAssist Breast data has also been compared to Oncotype DX, Mammaprint, Ki67, and IHC465

Besides robust data from Indian patients, other key advantages of CanAssist Breast include clear-cut division into two risk categories (no intermediate group) and its applicability to all patients, irrespective of their age or menopausal status. In fact, real-world data consist of 589 patients from 30 cities across India treated by 180 oncologists. Sankaran reported that the test shows $70 \%$ of patients fall in the low-risk group, whereas the remaining 30\% belong to the high risk. ${ }^{66}$ Furthermore, actual treatment administered to patients (chemotherapy or no chemotherapy) was consistent with the CanAssist Breast recommendation in as many as 93\% of instances, documenting its value in actual clinical practice.

Even during the COVID-19 pandemic, patients with EBC should be treated with curative intent. Hence, our treatment recommendations remain unchanged for patients with HR-positive Her2-negative EBC who are COVID-19 negative. ${ }^{67}$

We conclude that this study provides a robust practical consensus recommendation for the management of HR-positive Her2-negative patients with EBC following the principle of choosing wisely. ${ }^{68}$

\section{Conflict of Interest}

None declared.

\section{References}

1 Youlden DR, Cramb SM, Yip CH, Baade PD. Incidence and mortality of female breast cancer in the Asia-Pacific region. Cancer Biol Med 2014;11(2):101-115

2 Madhav MR, Nayagam SG, Biyani K, et al. Epidemiologic analysis of breast cancer incidence, prevalence, and mortality in India: protocol for a systematic review and meta-analyses. Medicine (Baltimore 2018;97(52):e13680, doi:10.1097/MD.0000000000013680PMID: 30593138

3 Malvia S, Bagadi SA, Dubey US, Saxena S. Epidemiology of breast cancer in Indian women. Asia Pac J Clin Oncol 2017;13(4):289-29510.1111/ajco.12661

4 Kokiwar PR, Kumar HB, Mubashare A. Epidemiological and clinical profile of breast cancer patients at a tertiary care hospital in South India. J Cancer Res Ther 2011;7(1):95, http:// www.cancerjournal.net/text.asp?2011/7/1/95/80445 [serial online]

5 Sharma D, Singh G. Breast cancer in young women: a retrospective study from tertiary care center of north India. South Asian J Cancer 2017;6(2):51-5310.4103/2278-330X.208859

6 Nair N, Shet T, Parmar V, et al. Breast cancer in a tertiary cancer center in India - An audit, with outcome analysis. Indian J Cancer 2018;55(1):16-2210.4103/ijc.IJC_484_17

7 Doval DC, Radhakrishna S, Tripathi R, et al. A multi-institutional real world data study from India of 3453 non-metastatic breast cancer patients undergoing upfront surgery. Sci Rep 2020;10(1):588610.1038/s41598-020-62618-3

8 Shet T. Improving accuracy of breast cancer biomarker testing in India. Indian J Med Res 2017;146(4):449-45810.4103/ijmr. IJMR_896_16

9 Parikh P, Puri T. Personalized medicine: lung cancer leads the way. Indian J Cancer 2013;50(2):77-79

10 Aggarwal S, Vaid A, Ramesh A, et al. Practical consensus recommendations on management of $\mathrm{HR}+$ ve early breast cancer with specific reference to genomic profiling. South Asian J Cancer 2018;7(2):96-10110.4103/sajc.sajc_110_18 
11 Monticciolo DL, Helvie MA, Hendrick RE. Current issues in the overdiagnosis and overtreatment of breast cancer. Am J Roentgenol 2018;210(2):285-291

12 Parikh PM, Hingmire SS, Bhavesh P, et al. Oncology Gold Standard $^{\mathrm{TM}}$ consensus statement on counseling patients for molecular testing and personalized cancer care. Int J Mol Immuno Oncol 2017;2:47-57 doi: 10.18203/issn.2456-3994. IntJMolImmunoOncol20172642

13 Parikh PM, Narayanan P, Vora A, et al. Conflict of interest disclosure and interpretation - rest assured the medical professional in the audience is perceptive, alert and smart. Int J Med Sci 2019;71:4-810.25259/IJMS_12_2019

14 Bapna A, Patni S, Patni N. A retrospective analysis of hormone receptor profile in breast cancer patients from a tertiary cancer center in Western part of India and study their relationship with Her $2 \mathrm{Neu}$ (IHC+FISH), age and menopausal States. Prensa Med Argent 2018;105:1-710.41720032-745X.1000353

15 Early Breast Cancer Trialists' Collaborative Group (EBCTCG). Effects of chemotherapy and hormonal therapy for early breast cancer on recurrence and 15-year survival: an overview of the randomised trials. Lancet 2005;365(9472) :1687-1717

16 Allemani C, Weir HK, Carreira H, et al; . CONCORD Working Group. Global surveillance of cancer survival 1995-2009: analysis of individual data for 25,676,887 patients from 279 population-based registries in 67 countries (CONCORD-2. Lancet 2015;385(9972):977-1010

17 Baik SH, Gallo LC, Wells KJ. Patient navigation in breast cancer treatment and survivorship: a systematic review. J Clin Oncol 2016;34(30):3686-3696

18 Regan MM, Francis PA, Pagani O, et al. Absolute benefit of adjuvant endocrine therapies for premenopausal women with hormone receptor-positive, human epidermal growth factor receptor 2-negative early breast cancer: TEXT and SOFT trials. JClinOncol2016;34(19):2221-223110.1200/JCO.2015.64.3171

19 Bedard PL, Cardoso F. Can some patients avoid adjuvant chemotherapy for early-stage breast cancer. ? Nat Rev Clin Oncol 2011;8(5):272-279

20 Chavez-MacGregor M, Clarke CA, Lichtensztajn DY, et al. Delayed initiation of adjuvant chemotherapy among patients with breast cancer. JAMA Oncol 2016;2(3):322-329

21 Brazda A, Estroff J, Euhus D, et al. Delays in time to treatment and survival impact in breast cancer. Ann Surg Oncol 2010; 17(Suppl 3) :291-296

22 Bhattacharyya GS, Doval DC, Desai CJ, et al. Overview of breast cancer and implications of overtreatment of early-stage breast cancer: an Indian perspective. JCO Glob Oncol 2020;6: 789-798 doi:10.1200/GO.20.00033PMID: 32511068

23 McLaughlin JM, Anderson RT, Ferketich AK, et al. Effect on survival of longer intervals between confirmed diagnosis and treatment initiation among low-income women with breast cancer. J Clin Oncol 2012;30(36):4493-4500

24 Regan MM, Pagani O, Francis PA; SOFT and TEXT Investigators and International Breast Cancer Study Group, et al; . Predictive value and clinical utility of centrally assessed ER, PgR, and Ki-67 to select adjuvant endocrine therapy for premenopausal women with hormone receptor-positive, HER2-negative early breast cancer: TEXT and SOFT trials. Breast Cancer Res Treat 2015;154(2):275-28610.1007/s10549-015-3612-Z

25 Ellis MJ, Tao Y, Luo J, et al. Outcome prediction for estrogen receptor-positive breast cancer based on postneoadjuvant endocrine therapy tumor characteristics. J Natl Cancer Inst 2008;100(19):1380-1388

26 Zhang Y, Schnabel CA, Schroeder BE, et al. Breast cancer index identifies early-stage estrogen receptor-positive breast cancer patients at risk for early- and late-distant recurrence. Clin Cancer Res 2013;19(15):4196-4205

27 Shin DW, Cho J, Kim SY, et al. Delay to curative surgery greater than 12 weeks is associated with increased mortality in patients with colorectal and breast cancer but not lung or thyroid cancer. Ann Surg Oncol 2013;20(8):2468-2476

28 Ho PJ, Cook AR, Binte Mohamed Ri NK, et al. Impact of delayed treatment in women diagnosed with breast cancer: a population-based study. Cancer Med 2020;9(7):2435-2444 10.1002/cam4.2830

29 Yang M, Rajan S, Issa AM. Cost effectiveness of gene expression profiling for early stage breast cancer: a decision-analytic model. Cancer 2012;118(20):5163-5170

30 Henry NL, Somerfield MR, Abramson VG, et al. Role of patient and disease factors in adjuvant systemic therapy decision making for early-stage, operable breast cancer: update of the ASCO Endorsement of the Cancer Care Ontario Guideline. J Clin Oncol 2019;37(22):1965-1977

31 Cardoso F, Kyriakides S, Ohno S; ESMO Guidelines Committee. Electronic address:, et al; , clinicalguidelines@esmo.org. Early breast cancer: ESMO Clinical Practice Guidelines for diagnosis, treatment and follow-up. Ann Oncol 2019;30(8):1194-1220 10.1093/annonc/mdz173

32 Telli ML, Gradishar WJ, Ward JH. NCCN Guidelines Updates: Breast Cancer. J Natl Compr Canc Netw 2019;17(5.5) :552-55510.6006/jnccn.20195006

33 Keam B, Im SA, Lim Y, et al. Clinical usefulness of AJCC response criteria for neoadjuvant chemotherapy in breast cancer. Ann Surg Oncol 2013;20(7):2242-2249

34 Sparano JA, Gray RJ, Ravdin PM, et al. Clinical and genomic risk to guide the use of adjuvant therapy for breast cancer. N Engl J Med 2019;380(25):2395-2405

35 Smith EC, Ziogas A, Anton-Culver H. Delay in surgical treatment and survival after breast cancer diagnosis in young women by race/ethnicity. JAMA Surg 2013;148(6):516-523

36 Thase ME, Parikh SV, Rothschild AJ, et al. Impact of pharmacogenomics on clinical outcomes for patients taking medications with gene-drug interactions in a randomized controlled trial. J Clin Psychiatry 2019;80(6):119-129 doi: 10.4088/JCP.19m12910

37 Badwe RA, Gangawal S, Mittra I, et al. Clinico-pathological features and prognosis of breast cancer in different religious communities in India. Indian J Cancer 1990;27(4):220-228

38 Na KY, Kim KS, Lee JE, et al. The 70-gene prognostic signature for Korean breast cancer patients. J Breast Cancer 2011; 14(1):33-38

39 Ishitobi M, Goranova TE, Komoike Y, et al. Clinical utility of the 70-gene MammaPrint profile in a Japanese population. Jpn J Clin Oncol 2010;40(6):508-512

40 Albain GJ, Sparano A, et al. Race, ethnicity and clinical outcomes in hormone receptor-positive, HER2-negative, node-negative breast cancer: results from the TAILORX trial. Oral presentation at: 2018 San Antonio Breast Cancer Symposium; December 4-8, 2018; San Antonio, TX. Abstract GS4-07.(https://www.ajmc.com/view)

41 Cardoso F, van't Veer LJ, Bogaerts J; MINDACT Investigators, et al. 70-gene signature as an aid to treatment decisions in early-stage breast cancer. N Engl J Med 2016;375(8):717-729

42 Filipits M, Rudas M, Jakesz R, et al. EP Investigators. A new molecular predictor of distant recurrence in ER-positive, HER2-negative breast cancer adds independent information to conventional clinical risk factors. Clin Cancer Res 2011; 17(18):6012-6020

43 Piccart MJ, Poncet C, Cardoso F, et al. Should age be integrated together with clinical and genomic risk for adjuvant chemotherapy decision in early luminal breast cancer? MINDACT results compared to those of TAILOR-X. Presented at: San Antonio Breast Cancer Symposium; December 10-14, 2019; San Antonio, TX. Abstract GS4-05. ( https://www.ajmc.com/ view/survival-consistent-for-women-with-early-stagebreast-cancer-despite-surgery-delays) 
44 Cardoso F, van't Veer L, Poncet C, et al. MINDACT: Long-term results of the large prospective trial testing the 70-gene signature MammaPrint as guidance for adjuvant chemotherapy in breast cancer patients. J Clin Oncol 2020;38(15_suppl) :506-50610.1200/JCO.2020.38.15_suppl.506

45 Dowsett M, Turner N. Estimating risk of recurrence for early breast cancer: integrating clinical and genomic risk. Available at: https://repository.icr.ac.uk/bitstream/handle/internal/ 3136/JCO\%20C\%20and\%20C\%20revised\%207\%20Nov\%2018\%20 (clean).pdf?sequence=6. Accessed December 30, 2021

46 Petkov VI, Kurian AW, Jakubowski DM, et al. Abstract P3-07-01: Breast cancer-specific mortality (BCSM) in patients age 50 years or younger with node-positive $(\mathrm{N}+)$ breast cancer $(\mathrm{BC})$ treated based on the 21-gene assay in clinical practice. Available at: https://clpmag.com/diagnostic-technologies/molecular-diagnostics/real-world-studies-support-utility-of-oncotypedx-to-guide-chemotherapy-treatment-for-breast-cancer/. Accessed on December 30, 2021

47 Fayaz S, Eissa HE, Demian GA. Implications of the 21-gene recurrence score assay (Oncotype DX) on adjuvant treatment decisions in ER-positive early-stage breast cancer patients: experience of Kuwait Cancer Control Center. J Egypt Natl Canc Inst 2020;32(1):1310.1186/s43046-020-00025-5

48 Schildgen V, Warm M, Brockmann M, Schildgen O. Oncotype DX Breast Cancer recurrence score resists inter-assay reproducibility with RT2-Profiler Multiplex RT-PCR. Sci Rep 2019;9(1):20266. doi: 10.1038/s41598-019-56910-0. PMID: 31889145; PMCID: PMC6937305

49 Orucevic A, Bell JL, King M, et al. Nomogram update based on TAILORx clinical trial results - Oncotype DX breast cancer recurrence score can be predicted using clinicopathologic data. Breast 2019;46:116-12510.1016/j.breast.2019.05.006

50 Agarwal G, Pradeep PV, Aggarwal V, et al. Spectrum of breast cancer in Asian women. World J Surg 2007;31(5):1031-1040

51 Yeo W, Ueno T, Lin CH; Asian Breast Cancer Cooperative Group, etal; . TreatingHR+/HER2-breastcancer in premenopausal Asian women:Asian BreastCancerCooperativeGroup2019Consensus and position on ovarian suppression. Breast Cancer Res Treat 2019;177(3):549-55910.1007/s10549-019-05318-5

52 Jung M, Choi EH, Nam CM, et al. Application of the adjuvant! Online model to Korean breast cancer patients: an assessment of prognostic accuracy and development of an alternative prognostic tool. Ann Surg Oncol 2013;20(8):2615-2624 10.1245/s10434-013-2956-z

53 Parikh PM, Aggarwal S, Hingmire S. Editorial. South Asian J Cancer 2018;7(2):67-68

54 Batra A, Patel A, Gupta VG, et al. Oncotype DX: where does it stand in India? J Glob Oncol 2019;5:1-2

55 Sarin R, Rath GK, Kumar S, et al. Consensus document for management of breast cancer 2016. http://cancerindia.org. in/wp-content/uploads/2017/11/Breast_Cancer.pdf. Accessed October 23, 2020
56 Parikh PM, Singh R. Why we should rely only on molecular tests based on Indian data. Int $\mathrm{J}$ Mol Immuno Oncol 2020;5:44-46

57 Wang SY, Chen T, Dang W, et al. Incorporating tumor characteristics to maximize 21-gene assay utility: a cost-effectiveness analysis. J Natl Compr Canc Netw 2019;17(1):39-46 https:// jnccn.org/view/journals/jnccn/17/1/article-p39.xml Accessed August 24, 2020

58 Bhoo-Pathy N, Yip CH, Hartman M, et al. Adjuvant! Online is overoptimistic in predicting survival of Asian breast cancer patients. Eur J Cancer 2012;48(7):982-989

59 Wong HS, Subramaniam S, Alias Z, et al. The predictive accuracy of PREDICT: a personalized decision-making tool for Southeast Asian women with breast cancer. Medicine (Baltimore 2015;94(8):e593

60 Engelhardt EG, Garvelink MM, de Haes JH, et al. Predicting and communicating the risk of recurrence and death in women with early-stage breast cancer: a systematic review of risk prediction models. J Clin Oncol 2014;32(3):238-250

61 Patil P, Bakre MM, Basavaraj C,et al. Can Assist breast: an affordable breast cancer prognostic test validated on Asian patients. Journal of Clinical Oncology 2020;38(15_suppl) :541-541

62 Attuluri AK, Serkad CPV, Gunda A, et al. Analytical validation of CanAssist-Breast: an immunohistochemistry based prognostic test for hormone receptor positive breast cancer patients. BMC Cancer 2019;19(1):24910.1186/s12885-019-5443-5

63 Bakre MM, Ramkumar C, Attuluri AK, et al. Clinical validation of an immunohistochemistry-based CanAssist-Breast test for distant recurrence prediction in hormone receptor-positive breast cancer patients. Cancer Med 2019;8(4):1755-1764 10.1002/cam4.2049

64 Ramkumar C, Buturovic L, Malpani S, et al. Development of a novel proteomic risk-classifier for prognostication of patients with early-stage hormone receptor-positive breast cancer. Biomark Insights 2018;13:117727191878910010.1177/1177 271918789100

65 Sengupta AK, Gunda A, Malpani S, et al. Comparison of breast cancer prognostic tests CanAssist Breast and Oncotype DX. Cancer Med 2020;9(21):7810-7818

66 Sankaran S, Dikshit JB, Prakash Sv C, Mallikarjuna SE, Somashekhar SP, Patil S, Kumar R, Prasad K, Shet D, Bakre MM. CanAssist Breast Impacting Clinical Treatment Decisions in Early-Stage HR+ Breast Cancer Patients: Indian Scenario. Indian J Surg Oncol 2021;12(Suppl 1):21-29. doi: 10.1007/ s13193-019-01014-4. Epub 2019 Dec 9. PMID: 33994724; PMCID: PMC8119549

67 Sheng JY, Santa-Maria CA, Mangini N, et al. Management of breast cancer during the COVID-19 pandemic: a stage-and subtype-specific approach. JCO Oncol Pract 2020;16(10): 665-674

68 Krishnamurthy A. Breast cancer prognostic tools: a promising Indian option. Int J Mol Immuno Oncol 2020;5:47-48 